\title{
Una intervención educativa podría mejorar la prescripción de antibióticos en infecciones respiratorias agudas
}

\author{
Educational intervention could improve antibiotic prescribing in acute respiratory tract infections
}

Gjelstad S y Col BMJ 2013; 347:44403

\section{Objetivo}

Evaluar los efectos de una intervención educativa en grupos de médicos de familia (MF) noruegos sobre la prescripción de antibióticos para el tratamiento de infecciones respiratorias agudas (IRA) comparándolo con un grupo control.

\section{Diseño, lugar y población}

Ensayo clínico controlado aleatorizado tipo cluster $^{*}$, donde la unidad de asignación al azar fueron grupos de MF por áreas geográficas; en Noruega. Fueron invitados a participar 250 grupos de médicos de familia; sólo 80 grupos aceptaron la invitación, de los cuales 79 grupos con 382 MF completaron la intervención.

\section{Intervención}

Consistió en dos encuentros grupales educativos con especialistas en MF, utilizando un modelo donde se evaluaban los datos de prescripción del profesional y se lo invitaba a reflexionar críticamente sobre la propia necesidad de cambio; además se realizó un seminario educativo de un día. En el primer encuentro se presentaron las recomendaciones generales según la guía clínica noruega para el uso de antibióticos en IRA. Cada participante recibió un programa de software que capturó los datos del sistema de registros del MF; a partir de lo cual se elaboró un informe individual mostrando la tasa de prescripciones y la distribución de antibióticos indicada para cada infección comparándola con las medias de los médicos participantes del mismo cluster. En el segundo encuentro se desarrolló una discusión utilizando como base los reportes de las prescripciones de antibióticos individuales y grupales. El grupo control recibió una intervención educativa, con la misma modalidad que el grupo intervención, dirigida al uso apropiado de medicamentos potencialmente inadecuados en pacientes mayores de 70 años, excluyendo como temática el uso de antibióticos. Un año después de finalizada la intervención se contactó a los participantes por correo para que realizaran una nueva captura de datos a fin de compararlos con los basales.

\section{Medición de resultados principales}

Se midió la tasa de prescripción de antibióticos y la proporción de penicilina $V$ prescritos en IRA antes y después de la intervención en ambos grupos.

\section{Resultados}

Los resultados principales se resumen en la tabla 1.

Tabla 1: Prescripción de antibióticos y de penicilina $V$ para IRA en ambos grupos antes y después de la intervención.

\begin{tabular}{|c|c|c|c|c|c|c|}
\hline \multirow{3}{*}{$\begin{array}{l}\text { Prescripción de } \\
\text { antibióticos en IRA }\end{array}$} & \multicolumn{2}{|c|}{$\begin{array}{c}\text { Grupo Intervención } \\
\qquad n=39\end{array}$} & $\begin{array}{l}\text { Cambio } \\
\text { (IC 95\%) }\end{array}$ & \multicolumn{2}{|c|}{$\begin{array}{l}\text { Grupo Control } \\
n=40\end{array}$} & \multirow[t]{2}{*}{$\begin{array}{l}\text { Cambio } \\
\text { (IC 95\%) }\end{array}$} \\
\hline & $\begin{array}{c}\text { Pre-intervención } \\
\%(\mathrm{IC} 95 \%)\end{array}$ & $\begin{array}{c}\text { Post-intervención } \\
\%(\mathrm{IC} 95 \%)\end{array}$ & & $\begin{array}{c}\text { Pre-intervención } \\
\%(\mathrm{IC} 95 \%)\end{array}$ & $\begin{array}{c}\text { Post-intervención } \\
\%(\mathrm{IC} 95 \%)\end{array}$ & \\
\hline & $\begin{array}{c}31,7 \\
(29,4 \text { a } 34,0) \\
\end{array}$ & $\begin{array}{c}30,4 \\
(27,9 \text { a } 32,8) \\
\end{array}$ & $-1,3(-2,4$ a $-0,2)$ & $\begin{array}{c}32,7 \\
(30,2 \text { a } 35,2) \\
\end{array}$ & $\begin{array}{c}34,2 \\
(31,5 \text { a } 37,0)\end{array}$ & $1,5(0,6$ a 2,4$)$ \\
\hline $\begin{array}{l}\text { Indicación de } \\
\text { Penicilina V }\end{array}$ & $\begin{array}{c}45,0 \\
(40,8 \text { a } 49,2)\end{array}$ & $\begin{array}{c}53,8 \\
(49,2 \text { a } 58,3)\end{array}$ & $8,8(5,7$ a 11,8$)$ & $\begin{array}{c}45,2 \\
(40,4 \text { a } 50,1)\end{array}$ & $\begin{array}{c}43,2 \\
(38,1 \mathrm{a} 48,2)\end{array}$ & $-2,0(-3,7$ a $-0,3)$ \\
\hline
\end{tabular}

Con respecto a la prescripción de antibióticos se observó en el grupo intervención una disminución estadísticamente significativa pero no clínicamente relevante ya que los autores al calcular el tamaño muestral esperaban una reducción de un tercio de las prescripciones.

\section{Conclusiones}

La intervención mejoró la prescripción de antibióticos para infecciones de las vías respiratorias en una muestra represen- tativa de médicos generales Noruegos y los cursos fueron viables para los profesionales. La intervención produjo una reducción estadísticamente significativa, aunque de relevancia clínica cuestionable, en la prescripción inadecuada de antibióticos en infecciones respiratorias agudas en médicos de atención primaria noruegos.

Fuentes de financiamiento: Norwegian Ministry of Health, the Norwegian Medical Association, and the Research Council of Norway.

\section{Comentario}

El uso excesivo de antibióticos está asociado a un aumento de la resistencia bacteriana y es motivo de preocupación de diversas instituciones médicas y gubernamentales a nivel mundial'. En el presente estudio se observó una redución en la tasa de prescripciones de antibióticos para el tratamiento de IRA, observándose una disminución de escasa relevancia clínica según lo esperado por los investigadores. Por otro lado se observó un aumento en el uso de antibióticos de espectro estrecho (penicilina $\mathrm{V}$ ) que podría promover una reducción en la resistencia antibiótica. Sin embargo el uso de penicilina $V$ en el tratamiento de IRA en otros países, como en la Argentina, no tiene un uso tan generalizado como en Noruega ${ }^{2}$ y esto podría comprometer la validez externa del estudio. En la actualidad, en la Argentina, no contamos con datos nacionales sobre las tasas de prescripción de antibióticos que puedan ayudarnos a estimar la magnitud del problema en nuestro país. El uso inapropiado de antibióticos es un problema con múltiples causas; futuras intervenciones deberían considerar la posibilidad de capacitar sobre esta problemática a quienes prescriben y dispensan medicamentos, a los pacientes y a la comunidad en general.

Laura Fraguas [ Servicio de Medicina Familiar del Hospital Italiano de Buenos Aires. laura.fraguas@ @ospitalitaliano.org.ar ]

Ver glosario

Fraguas L. Una intervención educativa podría mejorar la prescripción de antibióticos en infecciones respiratorias agudas. Evid Act Pract Ambul. 2015 ;18(1) 9. Ene-Mar.Comentado de: Gjelstad S, Høye S, Straand J, Brekke M, Dalen I, Lindbæk M. Improving antibiotic prescribing in acute respiratory tract infections: cluster randomised trial from Norwegian general practice (prescription peer academic detailing (Rx-PAD) study). BMJ. 2013 Jul 26;347:f4403. PMID: 23894178.

\section{Referencias}

1. Goossens H, Ferech M, Vander SR, Elseviers M. Outpatient antibiotic use in Europe and association with resistance: a cross-national database study. Lancet 2005; 365:579-87. 2. Adriaenssens N, Coenen S, Versporten A, Muller A, Minalu G, Faes C, et al. European Surveillance of Antimicrobial Consumption (ESAC): outpatient antibiotic use in Europe (1997-2009). J Antimicrob Chemother 2011; 66(suppl 6):vi3-12. 